\title{
PARTICULARIDADES DO MERCADO INTERNO DE BOVINOS NO BRASIL: ESTUDO DE CASO SOBRE O PROBLEMA DA BARGANHA NAS FEIRAS DE ANIMAIS DO INTERIOR DE ALAGOAS
}

\author{
José Adeilton da Silva Filho ${ }^{1}$ \\ André Maia Gomes Lages ${ }^{2}$ \\ Maria da Graça Derengowski Fonseca ${ }^{3}$
}

Resumo: Este trabalho apresenta uma análise sobre os efeitos da barganha em mercados agropecuários, mais especificamente o mercado bovino, a partir de um método de análise teórico e empírico. Utilizando-se de dados primários e secundários, e das teorias dos jogos cooperativos, por meio da solução de Nash e o teorema de Rubinstein, para assim evidenciar a desigualdade, que pode ocorrer nas negociações em feiras agropecuárias. Os resultados mostram uma desigualdade entre os possíveis preços entre comprador e vendedor, como também, o trabalho diagnosticou, por meio das teorias, que para adequação do preço correspondente com uma situação de igualdade no poder de barganha, seria necessário uma virtual flexibilização do ponto de desacordo do comprador, portanto em comparação com o modelo da solução de Nash haveria uma diferença no poder de barganha desfavorável ao vendedor. Os resultados mostram também uma diferença na paciência do vendedor logo confirmando também a existência de desvantagem para o vendedor durante as comercializações pelo modelo de Rubinstein.

Palavras-chave: Barganha. Agronegócio. Bovinos. Feiras. Alagoas.

\section{PARTICULARITIES OF THE DOMESTIC MARKET OF CATTLE IN BRAZIL: CASE STUDY ON THE PROBLEM OF BARGAINING AT ANIMAL FAIRS IN THE INTERIOR OF ALAGOAS}

Abstract: This paper presents an analysis of the effects of bargaining in agricultural markets, specifically the cattle market, based on a theoretical and empirical analysis method. Using primary and secondary data, and theories of cooperative games, through Nash's solution and Rubinstein's theorem, in order to evidence the inequality that can occur in negotiations at agricultural fairs. The results show an inequality between the possible prices between buyer and seller, as also the work diagnosed, through the theories, that for matching the corresponding price with a situation of equality in the bargaining power, it would be necessary a virtual easing of the point of disagreement of the buyer, so in comparison with the model of the Nash solution there would be a difference in bargaining power unfavorable to the seller. The results also show a difference in the seller's patience soon confirming also the existence of disadvantage for the seller during the commercializations by the model of Rubinstein. Keywords: Bargaining. Agrobusiness. Cattle. Fairs. Alagoas.

\footnotetext{
${ }^{1}$ Universidade Federal de Alagoas, Faculdade de Economia Adm. e Contabilidade-FEAC, Maceió, Brasil, adeilltonfilho@gmail.com https://orcid.org/0000-0001-6051-0289

2Universidade Federal de Alagoas, Faculdade de Economia Adm. e Contabilidade-FEAC, Maceió, Brasil, Andre_loages@msn.com, https://orcid.org/0000-0002-7447-9734

3Universidade Federal do Rio de Janeiro, Instituto de Economia-IE, Rio de Janeiro, Brasil, email@email.br, https://orcid.org/0000-0003-1106-9444
} 


\section{PARTICULARIDADES DEL MERCADO INTERNO DE BOVINOS EN BRASIL: ESTUDIO DE CASO SOBRE PROBLEMA DE LA NEGOCIACIÓN EN LAS FERIAS DE ANIMALES DEL INTERIOR DE ALAGOAS}

Resumen: Este trabajo presenta un análisis sobre los efectos de la negociación en mercados agropecuarios, más específicamente el mercado bovino, a partir de un método de análisis teórico y empírico. Utilizando datos primarios y secundarios, y de las teorías de los juegos cooperativos, a través de la solución de Nash y el teorema de Rubinstein, para así evidenciar la desigualdad, que puede ocurrir en las negociaciones en ferias agropecuarias. Los resultados muestran una desigualdad entre los posibles precios entre comprador y vendedor, así como el trabajo diagnosticó, por medio de las teorías, que para adecuación del precio correspondiente con una situación de igualdad en el poder de negociación, sería necesario una virtual flexibilización del punto de desacuerdo del comprador, por lo tanto en comparación con el modelo de la solución de Nash habría una diferencia en el poder de negociación desfavorable al vendedor. Los resultados muestran también una diferencia en la paciencia del vendedor luego confirmando también la existencia de desventaja para el vendedor durante las comercializaciones por el modelo de Rubinstein.

Palabras clave: Negociación. Agroindustria. Bovinos. Ferias. Alagoas.

\section{Introdução}

Este trabalho aborda uma análise, por meio de dados empíricos e teóricos a respeito do processo de comercialização, entre vendedores e compradores de bovinos em feiras. Especificamente, o problema da barganha existente nessas comercializações. Sendo a análise realizada por um estudo in loco nas feiras de gado em Alagoas, onde usa como recorte a feira de gado de Canafístula localizada no município de Palmeira dos Índios - AL, mesorregião do agreste de Alagoas, área de transição entre os biomas da Caatinga e a Mata Atlântica.

O trabalho aborda a problemática do poder desigual de barganha, ao realizar um estudo sobre esse mecanismo nas feiras de gado, que ocorrem no interior do estado de Alagoas, e a reflexão de dois principais questionamentos norteadores:

- Como o problema da barganha afeta o preço final, nas feiras comparando os preços médios propostos e acordados entre vendedor e comprador; e

- Se os resultados analisados auferem diferenças significativas no poder de comercialização, como podem ser contextualizados, e, portanto correlacionados com o que afirma a teoria dos jogos cooperativos.

O estado de Alagoas contém um total de 1.264 .053 animais (IBGE, 2016), no qual a região Nordeste concentra aproximadamente $22 \%$ do rebanho brasileiro. 
Consequentemente, os municípios do interior de Alagoas têm na pecuária uma de suas principais atividades econômicas. Segundo Lira (2007) adveio desde a concepção de Alagoas, quando os senhores de engenho precisavam criar animais, dentre os quais bovinos para auxiliar na produção de açúcar e na pecuária. "Os senhores de engenho, necessitando de muitos animais para exercerem várias tarefas nos canaviais, passaram a criar cavalos, burros e bovinos [...]" (LIRA, 2007, p. 14, grifo nosso).

As tradicionais feiras de animais, conhecidas também como feira de gado, é um comércio popular presente em grande parte desses municípios interioranos do Estado de Alagoas, assim como em outras partes do Brasil, que serve como meio de transacionar os animais excedentes, produzidos nas fazendas, para outras finalidades, como, por exemplo; engorda, recria e abate.

Na feira de gado, operários da construção civil, comerciantes, vigilantes,
motoristas de ônibus, médicos, advogados e pecuaristas, que têm em
comum o "gosto pelo gado", aproveitam a manhã de domingo para se
encontrar, conversar, "olhar o gado" e também fazer negócios (MAIA, 2007,
p.22).

A Feira de Gado se mostra como um mercado de grande significado cultural e econômico para a população do Nordeste do Brasil, consequentemente para Alagoas. Como em toda a feira, pessoas de diversas classes sociais buscam se socializar no ambiente de comércio, por meio das trocas, para assim viabilizar suas produções e suas demandas. Utilizando-se, assim, da feira como importante canal de comercialização.

O problema da barganha é tratado dentro da teoria dos jogos, mais precisamente nos jogos cooperativos. Tais jogos cooperativos, segundo Nash (1950), podem ser retratado por meio de uma situação de barganha entre duas pessoas, ou seja, que representa dois indivíduos que podem se beneficiar, em mais de um modo, mutuamente em cooperação. Um caso simples ocorre quando nenhuma ação de um dos indivíduos pode afetar o bem-estar do outro sem que isso seja de conhecimento do outro indivíduo.

Diante dessa realidade, o objetivo essencial deste estudo é apresentar como a barganha pode ser representativa no preço final acordado nas negociações, onde nem sempre o resultado, demonstre-se satisfatório, portanto de maneira igual para ambas as partes, logo apresentando uma significativa diferença no poder de barganha, e dessa maneira, por meio da teoria dos jogos podem dar respaldo aos resultados de dados empíricos coletados em pesquisa. 
Para alcançar esses objetivos se fará uma breve explicação da feira, posteriormente das teorias que envolvem a barganha, onde serão abordadas duas teorias, a denominada solução de Nash (1950) e o Teorema de Rubinstein (1982). Como também a bibliografia de outros autores, além de dados primários realizados em pesquisa local, e dados secundários, por meio da Agência de Defesa e Inspeção Agropecuária de Alagoas - ADEAL, e seus dados do Sistema de Defesa Agropecuária - SIDAGRO.

\section{O Problema da Barganha e A Solução de Nash}

A solução de Nash está implícita pelos seguintes axiomas: Axioma da Eficiência de Pareto (EP), Axioma da Racionalidade Individual (RI), Axioma da Invariância a Transformações Afins Positivas (ITAP), Axioma da Independência das Alternativas Irrelevantes (IAI), Axioma da Simetria (SM). O grande mérito desse modelo é conseguir a unicidade de solucionar o problema da barganha satisfazendo todos esses axiomas.

O axioma EP imprime que a solução compete ao conjunto $S$, assim cada jogador pertence ao conjunto de utilidades viáveis para ambos, assegurando que não há outra rota para a solução cooperativa além do conjunto $S$, desse modo não há nada que os jogadores possam fazer que melhore o resultado para ambos. $O$ axioma $\mathrm{RI}$ afirma que os jogadores são racionais, sendo assim buscam sempre obter o maior valor possível, caso o valor da discórdia superar o valor de uma possível negociação, será preferível o jogo não-cooperativo. O axioma ITAP, referese ao fato da negociação passar por uma mudança afim positiva com valor dos pontos de desacordo, assim um novo jogo é criado, embora o resultado da divisão das partes continue sendo a mesma. O axioma IAI significa que ao se eliminar alternativas do conjunto de utilidades, cria-se um novo jogo, embora não se altera o resultado da divisão da barganha, permanecendo a mesma divisão do jogo original. O último axioma é o da SM, que afirma que ambos os jogadores devem receber a divisão em partes iguais, pois tendo os jogadores posições simétricas, tanto no ponto de discórdia, como também no conjunto de utilidades, o resultado da solução de Nash corresponderá 50\% para cada jogador (SANTOS, 2009).

Sendo U a união dos ganhos de dois jogadores, e assim Uv e Uc os valores, respectivamente, de vendedor e comprador resultantes de um jogo de barganha 
cooperativo. Seja $W_{v}$ a participação do vendedor e $W_{c}$ a participação do comprador, com $W_{v}+W_{C}=1$, e $U$ a união dos ganhos, assim:

$$
\mathrm{Wv} . \mathrm{U}=\mathrm{Uv} \text { e } \mathrm{W}_{\mathrm{C}} \mathrm{U} \mathrm{U}=\mathrm{UC} \text {. }
$$

Segundo Dias (2005), um jogo cooperativo de barganha é definido pelo conjunto factível e pelo ponto de desacordo, o par $(S, d)$, sendo $S$ um conjunto convexo, limitado, fechado e com, pelo menos, um ponto dominando estritamente $o$ ponto $d, d \in S$, pode se definir as participações na solução de Nash com a seguinte equação:

$W v=1 / 2+(d v-d c) /(2 U), U>0$ eWve(0,1).

Já para $W_{c}$ pode ser representado assim:

$W_{\mathrm{C}}=1-\mathrm{W}_{\mathrm{V}}$.

Formalmente, além de ser a única a atender aos axiomas anteriormente mencionados, a solução de Nash $N(S$, d) é o resultado do seguinte problema de maximização (DIAS, 2005):

$\mathrm{N}(\mathrm{S}, \mathrm{d})=\operatorname{argmax}\left\{\left(\mathrm{Uv}_{\mathrm{v}}-\mathrm{dv}\right)\left(\mathrm{Uc}_{\mathrm{c}}-\mathrm{dc}\right) \mid\left(\mathrm{Uv}_{\mathrm{v}}, \mathrm{U}_{\mathrm{c}}\right) \in \mathrm{S}, \mathrm{U}_{\mathrm{v}} \geq \mathrm{dv}, \mathrm{U}_{\mathrm{c}} \geq \mathrm{dc}_{\mathrm{c}}\right\}$

Portanto em uma situação, onde o ponto de desacordo $d$ não for preferível para o vendedor $d v$, tão pouco para o comprador $d_{C}$, dentre o conjunto de soluções possíveis $S$, a solução de Nash, respeitando os axiomas descritos anteriormente, consegue identificar o ponto ótimo, que consequentemente representa o resultado do jogo.

\section{O Modelo de Rubinstein}

Para Rubinstein, a solução do jogo de barganha decorre de uma visão, onde para especificar a barganha, o processo deve decorrer sem utilização da abordagem axiomática de Nash, mas sim, através de um modelo dinâmico com a solução decorrente de ofertas alternadas. Surgindo, deste modo, o seu teorema presente no trabalho intitulado "Perferct equilibrium in a bargaining model" de 1982. (BIERMAN, 2013)

Neste artigo, adotarei a abordagem estratégica. Considerarei a seguinte situação de barganha: dois jogadores devem chegar a um acordo sobre a partição de uma torta de tamanho 1. Cada uma deve fazer, por sua vez, uma proposta sobre como deve ser dividida. Depois que uma das partes fez essa oferta, a outra deve decidir, quer para aceitá-la, quer rejeitá-la, e continuar com a barganha. As relações de preferência dos jogadores são definidas no conjunto de pares ordenados do tipo $(x, t)$ (onde 0 ' $x$ ' -1 e t é 
um inteiro não negativo). O par ( $x, t)$ é interpretado como "1 recebe $x$ e 2 recebe 1 - $x$ no tempo t"(RUBINSTEIN, 1982, p.98, tradução nossa $\left.{ }^{4}\right)$.

No referido modelo desenvolvido, presume-se que ambos têm informações completas, como também, que além de um custo de negociação exista um fator de desconto a cada rodada, sendo ambos fixos. Supondo que dois jogadores, $V$ e $C$, estejam barganhando, por meio de ofertas que se alternam (como na feira de gado), um valor que corresponde a um excedente. $O$ jogador $C$ faz a primeira oferta sem um limite definido de ofertas com um fator de desconto no tempo para cada oferta de $0<\delta_{v}<1$ e $0<\delta_{c}<1$, sendo que aceitam ofertas quando se tornam indiferentes a elas. Deste modo, existe apenas um equilíbrio perfeito em subjogos no qual $C$ oferece de imediato a $V$ a fração:

$$
\delta_{v} \cdot\left(1-\delta_{c}\right) /\left(1-\delta_{v} \cdot \delta_{c}\right)
$$

do excedente e retém:

$$
\left(1-\delta_{v}\right) /\left(1-\delta_{v} . \delta_{c}\right)
$$

para si mesmo, sendo essa a oferta que o jogador $V$ acolhe. (BIERMAN, 2013)

Deste modo, ao contrário do modelo de Nash, que focou sua solução na determinação do ponto de desacordo. Rubinstein mostra nos resultados presentes nas fórmulas 5 e 6 , que o fator de desconto no tempo, ou seja, a paciência do jogador, torna-se determinante para a solução do jogo, assim como a decisão do primeiro a se mover.

\section{Metodologia}

O tipo de pesquisa constitui-se de caráter descritivo e exploratório com estudo de caso, nesse quadro, o estudo preserva certa dose pioneirismo em nível local. A aplicação do método será feita através de visitas in loco, na feira de gado do povoado de Canafístula de Frei Damião no município de Palmeira dos Índios - AL. Foi também utilizado, além dos dados primários da feira de Canafístula, dados

\footnotetext{
${ }^{4}$ In this paper I will adopt the strategic approach. I will consider the following bargaining situation: two players have to reach an agreement on the partition of a pie of size 1. Each has to make in turn, a proposal as to how it should be divided. After one party has made such an offer, the other must decide either to accept it or to reject it and continue with the bargaining. The players' preference relations are defined on the set of ordered pairs of the type $(x, t)$ (where 0 ' $x$ ' -1 and $t$ is a nonnegative integer). The pair $(x, t)$ is interpreted as "1 receives $x$ and 2 receives $1-x$ at time t."
} 
secundários coletados no Sistema de Defesa Agropecuária de Alagoas (SIDAGRO$A L)$ das três feiras mais importantes do estado, que segundo a Agência de Defesa e Inspeção Agropecuária de Alagoas (ADEAL) tratam-se das Feiras de Dois Riachos, Canafístula e Canapi.

Os dados secundários do SIDAGRO-AL advêm da necessidade de mensurar o número real de negociações realizadas na feira, sendo as negociações a população estudada, e, assim encontrar o número finito amostral factível para aplicação do questionário quantitativo com dados referentes aos preços pagos por grupo de consumidores existentes nas negociações, para determinados tipos de animais, sendo um critério para a inferência da amostra, que foi obtida na ADEAL. Além de apresentar o volume de saídas e entradas, finalidades de compra das três maiores feiras do estado, para melhor contextualizar o objeto de estudo.

Para descrever o ambiente de comércio e os tipos de agentes (vendedor e comprador), assim como os valores pagos por eles, através dos questionários aplicados na feira estudada, se seguiram as consecutivas etapas:

- Realização de visitas in loco para o conhecimento da feira de gado de Canafístula, e as suas práticas comerciais;

- Aplicação de questionário aos vendedores e compradores, que somente fecharam acordo de compra e venda, nas feiras; e

- Levantamento de dados sobre as feiras, no Sistema de Defesa Agropecuária de Alagoas (SIDAGRO-AL), para tomar conhecimento da quantidade de negociações realizadas nas feiras, cujo objetivo é extrair a amostra finita de negociações.

\section{Amostragem}

Amostragem Aleatória Simples, onde cada negociação foi coletada de maneira randômica, com a utilização da entropia existente no processo e percurso das negociações, mediante entrevistas na sala de emissão da Guia de Trânsito Animal (GTA), localizada na própria feira, deste modo oferecendo a cada negociação, oriunda da população, a mesma probabilidade de ser incluída na extração.

A determinação do valor médio pago de cada consumidor para um conjunto específico de animais na feira foi obtida com base na estimativa da variável 
quantitativa, com desvio padrão desconhecido e população finita, através da seguinte fórmula:

$$
n=\frac{Z^{2} \cdot S^{2} \cdot N}{Z^{2} \cdot S^{2}+e^{2} \cdot(N-1)}
$$

onde:

$$
\begin{aligned}
& N=\text { tamanho da população } \\
& Z=\text { nível de confiança } \\
& S^{2}=\text { Desvio padrão da amostra piloto } \\
& e=\text { erro do estudo piloto }
\end{aligned}
$$

Deste modo $N$ foi originário do número de negociações realizadas nos dias de feira, no qual foi aplicado o questionário. Entretanto os dados só foram disponibilizados ao final de cada feira, quando a pesquisa já tinha sido completada, porém, utilizou-se como base a quantidade de negociações realizadas na pesquisa piloto. A amostra piloto foi realizada no dia 28 de agosto de 2017, na feira de gado de Canafístula. As pesquisas com aplicação do questionário foram realizadas durante os eventos das feiras, que o correram durante todo o mês de novembro de 2017, em Canafístula de Frei Damião, povoado do município de Palmeira dos Índios, Alagoas.

Para diagnosticar o diferencial de poder de barganha do produtor em relação ao consumidor, utilizou-se o método desenvolvido por John Forbers Nash Jr, denominado solução de Nash para jogos cooperativos, como também o modelo de Rubinstein. No modelo da solução de Nash, os dados coletados a partir dos questionários, foram introduzidos na fórmula 01 , onde os valores do ponto de desacordo do vendedor se convencionaram pelo preço inicial do comprador, e para o comprador o preço inicial do vendedor, obtido no questionário sobre a forma das seguintes perguntas, qual o "valor pedido", "qual o valor ofertado", e por fim "qual o valor comprado", sendo esse último o parâmetro, comparou-se com o ponto ótimo da solução de Nash.

Para o modelo de Rubinstein foi feita uma verificação na diferença de paciência entre os jogadores, através de perguntas feitas com relação ao custo de espera, ou seja, foi questionado aos vendedores, qual seu custo caso não venda o 
animal, e ao comprador qual o seu custo caso não compre o animal, posteriormente se fez a comparação da validade teórica com os resultados obtidos, logo de modo empírico, através da diferença entre os custos relatados pelo comprador e pelo vendedor.

\section{Caracterização do Objeto de Estudo}

As três principais feiras de gado segundo a ADEAL são as feiras de Dois Riachos, Canafístula e Canapi, A feira de Dois Riachos está localizada no município de mesmo nome na margem esquerda da BR-316 sentido Leste para Oeste, já a feira de Canafístula se encontra no povoado de Canafístula de Frei Damião no Município de Palmeira dos Índios/AL, ficando também no mesmo sentido da margem esquerda da BR-316, enquanto a feira de Canapi situa-se um pouco afasta dada cidade, de mesmo nome, na margem direita no mesmo sentido da BR-316.

\section{Figura 1: Localização aproximada das feiras no mapa político do estado de Alagoas}

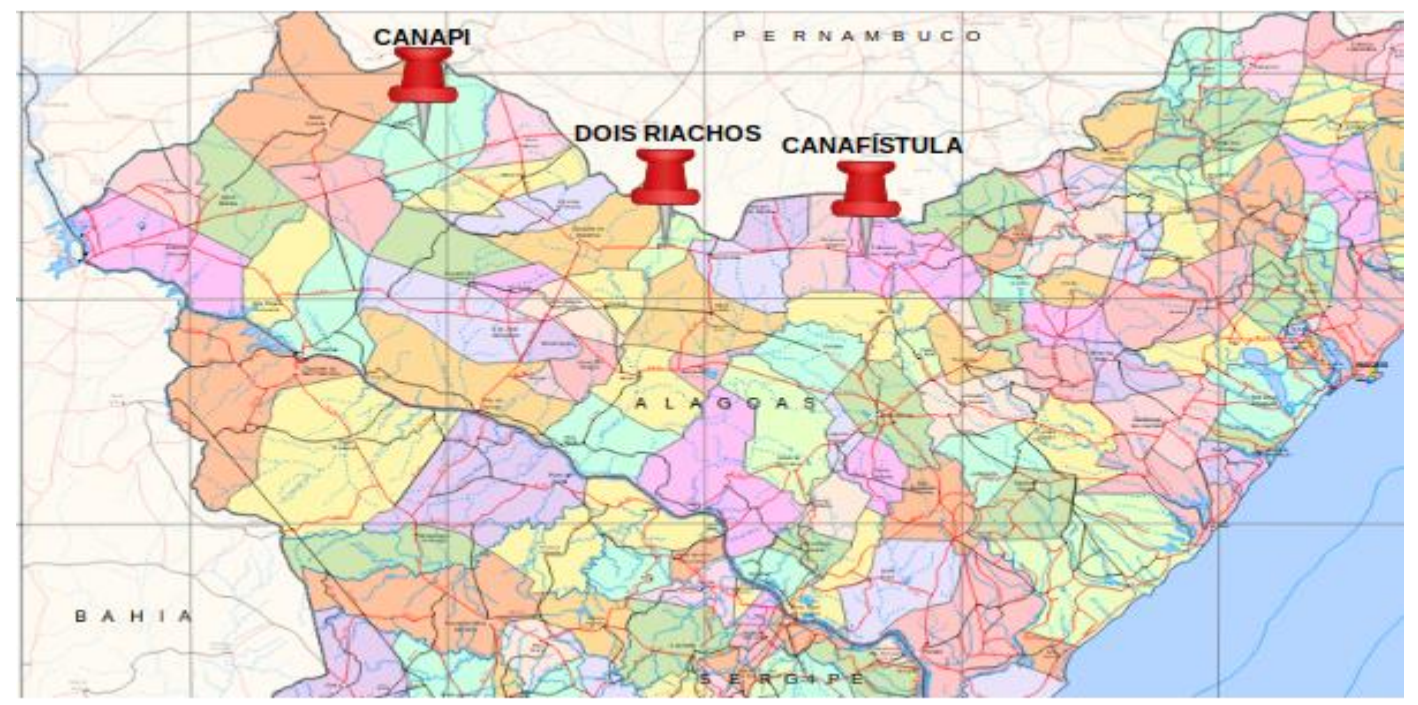

Fonte: IBGE, 2015. Adaptada pelos autores.

A feira de Dois Riachos ocorre, assim como na feira de Canapi, toda quartafeira, já a feira de Canafístula ocorre toda a segunda-feira. Segundo os dados adquiridos na ADEAL, o maior volume de entradas (oferta) e saídas (vendas) de animais, encontra-se na feira de Dois Riachos que é, sem dúvida, a maior feira de gado em volume de todo estado de Alagoas. As feiras de Canafístula e Canapi representam em volume o segundo e terceiro lugar respectivamente, conforme os 
dados disponibilizados. Os dados, que foram entregues, correspondem ao período de 2014 até 2016, com os dados de entrada, saída, destino e finalidade de compra.

Tabela 1- Total de entradas de bovinos separados em sexo, nas três feiras nos anos de 2014, 2015 e 2016.

\begin{tabular}{c|c|c|c|c|}
\hline $\begin{array}{c}\text { Feira de } \\
\text { gado }\end{array}$ & Ano & $\begin{array}{c}\text { Entrada } \\
\text { de } \\
\text { Machos }\end{array}$ & $\begin{array}{c}\text { Entrada } \\
\text { de } \\
\text { Fêmeas }\end{array}$ & $\begin{array}{c}\text { Entradas } \\
\text { totais }\end{array}$ \\
\hline \multirow{3}{*}{$\begin{array}{c}\text { Dois } \\
\text { Riachos }\end{array}$} & 2014 & 41130 & 20161 & 61291 \\
\cline { 2 - 5 } & 2015 & 43667 & 27953 & 71620 \\
\cline { 2 - 5 } & 2016 & 83551 & 49489 & 133040 \\
\hline \multirow{3}{*}{ Canafístula } & 2014 & 1984 & 1071 & 3055 \\
\cline { 2 - 5 } & 2015 & 17302 & 13240 & 30542 \\
\cline { 2 - 5 } & 2016 & 26800 & 19014 & 45814 \\
\hline \multirow{3}{*}{ Canapi } & 2014 & 6130 & 2142 & 8272 \\
\cline { 2 - 5 } & 2015 & 6105 & 2816 & 8921 \\
\cline { 2 - 5 } & 2016 & 6667 & 3857 & 10524 \\
\hline
\end{tabular}

Fonte: ADEAL, 2017

Por meio da tabela 01, pode-se evidenciar o quanto pode ser expressiva a quantidade de bovinos que se dirigem todos os anos para os currais das feiras de gado em cada um dos municípios. Somente nos três anos analisados, se somados todas as três feiras, resultaram no valor de 373.079 animais, que representa aproximadamente $30 \%$ do rebanho Alagoano, esse número poderia ser maior se a feira de Canafístula em 2014 estivesse com os cadastros dos produtores no SIDAGRO em sua plenitude de adesão e funcionamento, o que só foi possível em 2015, por isso a discrepância dos dados, enquanto que, nas demais feiras tudo está constante. Em outras palavras, acontecia, de na feira de Canafístula, ter ocorrido até 2014, comercialização em parte menor dos casos sem uso da GTA (Guia de Trânsito Animal). Esse problema foi rapidamente corrigido pelas exigências feitas nesse quadro pela ADEAL. Nas outras duas feiras tudo tinha ficado como dantes por conta de que não havia registro de problema. 
Tabela 2- Total de bovinos negociados separados em sexo, nas três feiras nos anos de 2014, 2015 e 2016.

\begin{tabular}{c|c|c|c|c|}
\hline $\begin{array}{c}\text { Feira de } \\
\text { gado }\end{array}$ & Ano & $\begin{array}{c}\text { Saída de } \\
\text { Machos }\end{array}$ & $\begin{array}{c}\text { Saídas } \\
\text { de } \\
\text { Fêmeas }\end{array}$ & $\begin{array}{c}\text { Saídas } \\
\text { totais }\end{array}$ \\
\hline \multirow{2}{*}{$\begin{array}{c}\text { Dois } \\
\text { Riachos }\end{array}$} & 2014 & 15924 & 6847 & 22771 \\
\cline { 2 - 5 } & 2015 & 17451 & 9977 & 27429 \\
\cline { 2 - 5 } & 2016 & 27070 & 15234 & 42306 \\
\hline \multirow{2}{*}{ Canafístula } & 2014 & 628 & 383 & 1011 \\
\cline { 2 - 5 } & 2015 & 5636 & 3901 & 9537 \\
\cline { 2 - 5 } & 2016 & 7082 & 5173 & 12255 \\
\hline \multirow{2}{*}{ Canapi } & 2014 & 2537 & 903 & 3440 \\
\cline { 2 - 5 } & 2015 & 2913 & 1314 & 4227 \\
\cline { 2 - 5 } & 2016 & 2610 & 1445 & 4055 \\
\hline Fonte: ADEAL, 2017 & & &
\end{tabular}

Após observar a oferta de animais nas feiras, a tabela 02 apresenta a demanda, ou seja, a saída dos animais que foram comprados nos currais das três feiras de gado, nos anos analisados, separados em sexo, como também a sua soma total. Dois Riachos representa, obviamente, o maior número de vendas com um total de 42.306 animais, seguido de Canafístula com 12.255 e Canapi com 4.055 animais no ano de 2016. Desta forma, observa-se que ao todo somando se os três anos analisados a venda total foi de 127.031 animais, logo a demanda por animais é menor que a oferta nos currais da feira de gado, no comparativo com a oferta de 373.079 quando somados os valores totais da tabela 01 .

A tabela 02 mostra também que as quantidades de machos vendidos em 2016 em Dois Riachos foram de 27.070 animais, enquanto as vendas de animais fêmeas foram de 15.234, seguido de Canafístula com 7.082 machos e 5.173 fêmeas, enquanto Canapi com uma venda de 2.610 machos e 1.445 fêmeas. Quando comparado com a tabela 01 machos e fêmeas têm um rendimento muito próximo em vendas, pois ambos representam em média aproximadamente $30 \%$ de vendas em comparação com a oferta total. 


\section{Gráfico1-Os municípios com quantidade acima de $1 \%$ do total de animais adquiridos em Alagoas de 2014 até 2016.}

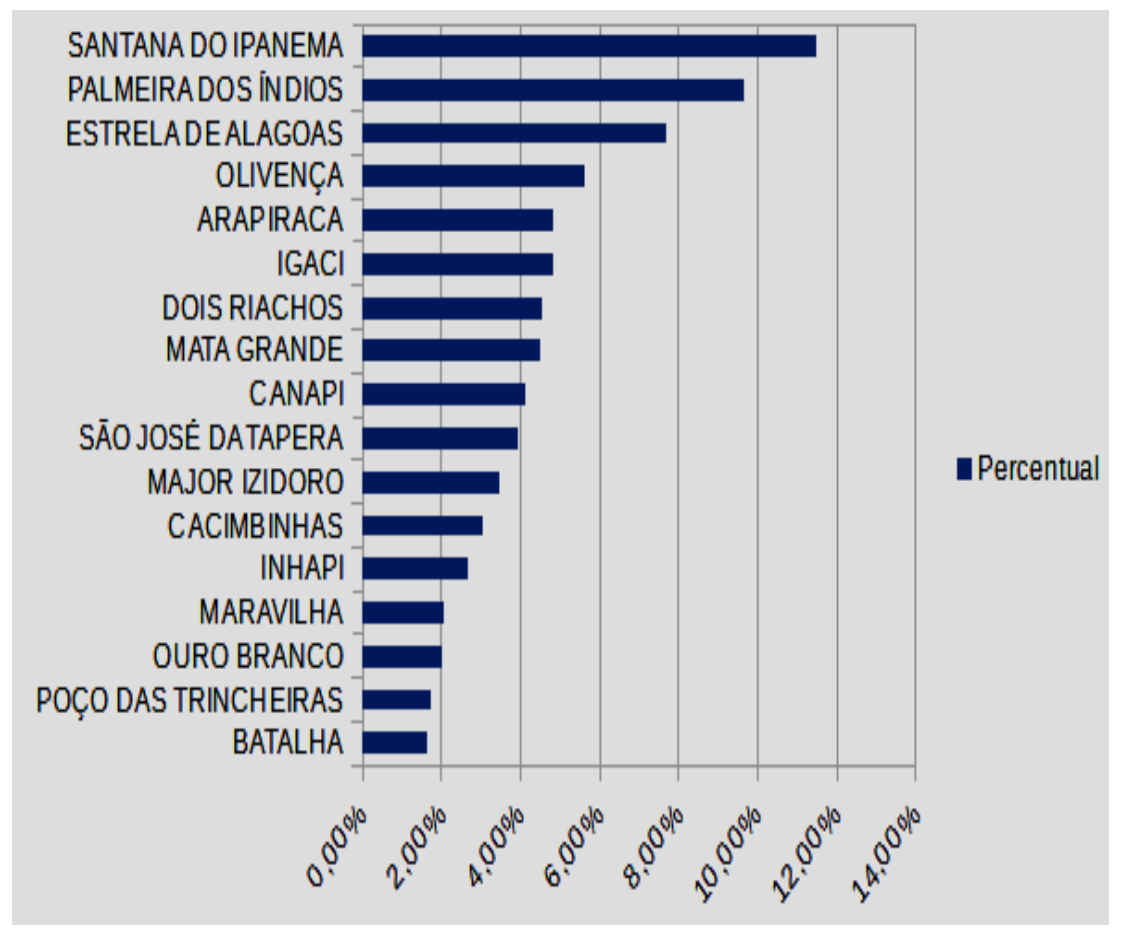

Fonte: ADEAL, 2017

Os municípios alagoanos que adquirem os animais nas três feiras de gado são ao todo 88 , somente no período analisado. Isso corresponde a $86,27 \%$ dos 102 municípios do estado. O município que apresenta o maior destino dos animais comercializados nas feiras fica na mesorregião do sertão alagoano: Santana do Ipanema, com quase $12 \%$ do total adquirido dentro do estado. Seguido por Palmeira dos Índios e Estrela de Alagoas, com mais de $8 \%$ e $6 \%$ do volume total de saídas durante o período analisado, respectivamente, conforme apresenta o gráfico 01. 


\section{Gráfico 2 - Municípios com quantidade acima de $1 \%$ do total de animais adquiridos por Pernambuco de 2014 até 2016.}

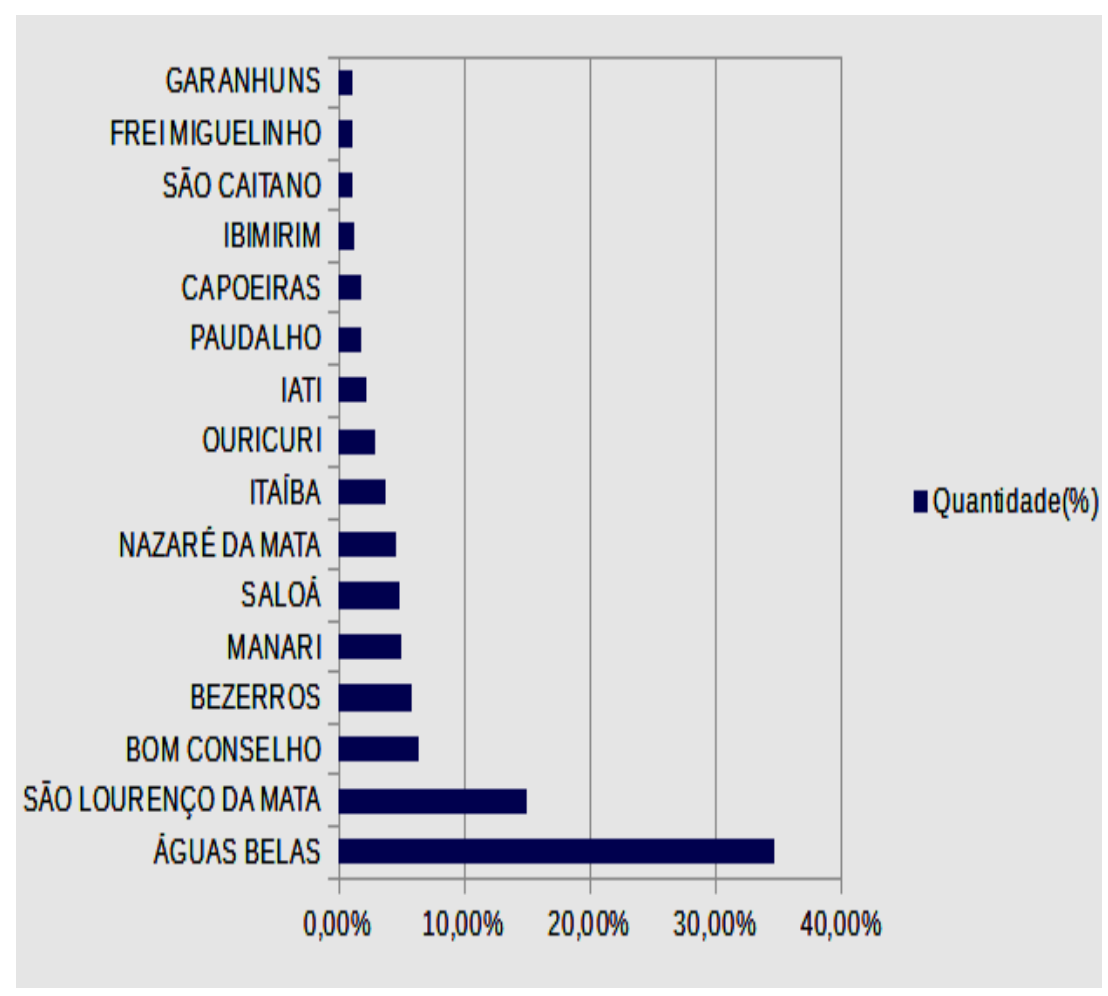

Fonte: ADEAL, 2017

O estado nordestino que mais importa animais das três feiras alagoanas é Pernambuco, com um total de 36 municípios registrados durante o período analisado. O município pernambucano com o maior volume de compra é Águas Belas que representa mais de $30 \%$ das importações do estado. O gráfico 02 apresenta os demais municípios que importam gados oriundos das feiras alagoanas com um volume mínimo de 1\%, onde, além de Águas Belas, nota-se a importância de municípios como São Lourenço da Mata, (bem próxima de Recife); Bom Conselho e Bezerros, que juntas somam mais de $20 \%$ de importações. Tal fato se deve a proximidade de Pernambuco com Alagoas. O município de Bom Conselho, por exemplo, fica apenas aproximadamente $33 \mathrm{~km}$ da feira de Canafístula, como também Águas Belas, que fica à aproximadamente $61 \mathrm{~km}$ de Canapi. 


\section{Gráfico 3 - Volume de saída para municípios de Sergipe de 2014 até 2016.}

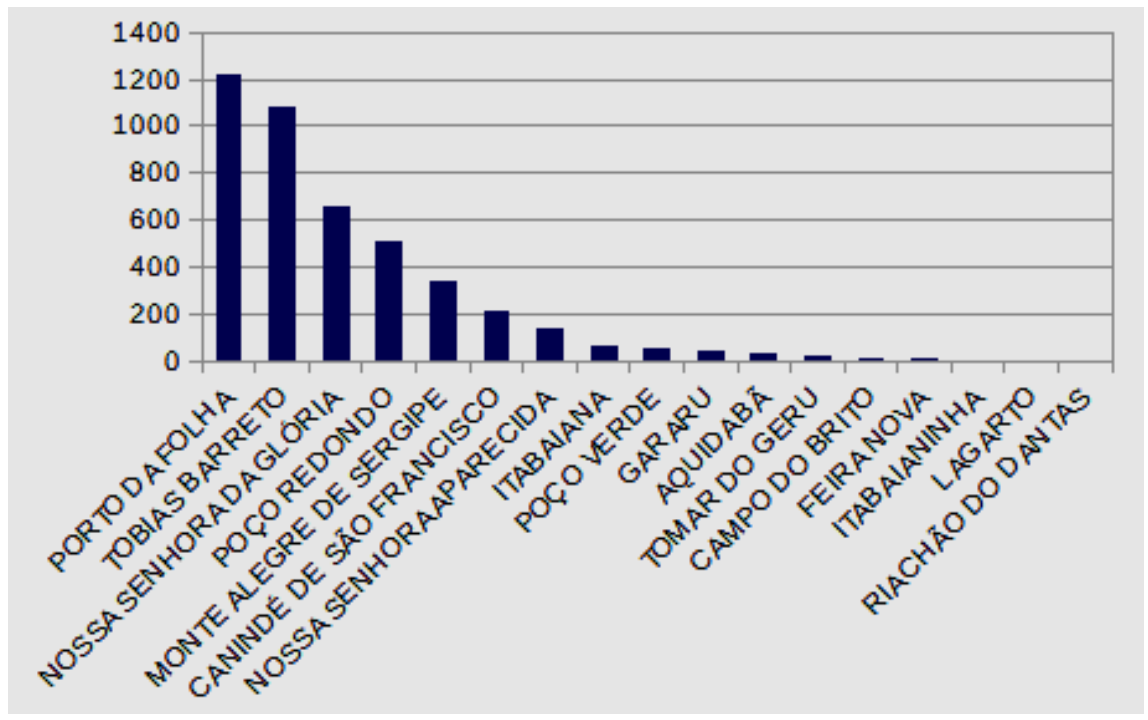

Fonte: ADEAL, 2017

O Gráfico 03 apresenta todos os 17 municípios de Sergipe que adquiriram animais da feira de Dois Riachos durante o período analisado. Os três maiores municípios em volume de compra foram Porto da Folha com valores acima de 1.200 animais, seguido de Tobias Barreto com valores acima de 1.000 animais e Nossa Senhora da Glória com valores acima de 600 animais. Nota-se que a feira é ponto de visita por parte de alguns negociadores de bovinos sergipanos, a exemplos dos compradores com destino ao município de Tobias Barreto, que fica a $287 \mathrm{~km}$ dos currais da feira de Dois Riachos.

\section{Resultados e Discussões}

O mecanismo de mercado spot existente nas feiras de gado no interior de Alagoas, assim como todo mercado, tem no preço um referencial para as realizações das trocas, deste modo o preço exibe papel fundamental para coordenação e funcionamento do evento. Nas feiras, o preço da arroba é a principal referência, exibindo um valor que é construído no mercado entre frigoríficos e consumidores, logo, pode-se denominar tal mercado de "o mercado das carnes". Deste modo, pode ser observado que tal referência para o comércio da feira de gado é mais tangível para os consumidores com finalidade de abate, do que para os demais consumidores existentes na feira, onde o objetivo do comprador está em adquirir o animal, por no mínimo, seu preço de arroba. 
É importante salientar, também, que tal preço de arroba vai depender do rendimento de carcaça, onde tal rendimento consiste na interpretação de ambos, onde a solução se dá mediante apenas o mecanismo de barganha. Todo processo ocorre baseado apenas na visualização dos animais e baseado na experiência e intenções de cada agente envolvido na negociação.

Em muitas ocasiões o vendedor tenta mostra especificidades de seus animais para poder distanciar para cima seu preço do preço da arroba, e assim, poder obter um lucro maior, porém isso é bastante difícil, afinal decorre de subjetividades, logo, torna-se difícil para o vendedor saber qual o real preço de reserva do potencial consumidor, durante a negociação. Os vendedores comumente entram com um preço mais alto, e vão decaindo o preço até que ambos (compradores e vendedores) cooperativamente acertem um acordo. Porém nem sempre esse jogo termina em uma situação justa, ou seja, em uma divisão igual das partes. No intuito de observar essa diferença, foram adquiridos os valores de preço de oferta e demanda, além do preço de compra por arroba, das negociações a fim de comparação.

Os valores, de oferta e demanda, servem como comparativo entre a diferença do poder de barganha existente entre compradores e vendedores na feira de gado. O valor médio do preço por arroba ofertado, durante o período analisado, foi de $R \$ 162,80$ já o preço médio demandado por arroba foi de $R \$ 142,30$, e o preço médio de compra por arroba foi de $\mathrm{R} \$ 145,34$, logo, nota-se que o valor tende a estar mais próximo do preço do comprador que do vendedor. De forma mais precisa, essa diferença do poder de barganha, pode ser explicada, por meio do modelo da solução de Nash (NASH, 1950) para jogos cooperativos, usando a fórmula 01, onde se obteve o seguinte resultado:

O valor que está em disputa é o payoff 20,50 dado dc - dv ( $R \$ 162,80$ $\mathrm{R} \$ 142,30)$.

Sendo $W_{v}$ encontrado por meio da fórmula 04 , ao atribuir os valores, a parte que o vendedor deve ceder é encontrada do seguinte modo;

$W_{v}=1 / 2+(20,50-20,50) /(2 \cdot 20,50)$

logo;

$W_{v}=0,5$

portanto, deve-se ceder $1 / 2$, ou seja $-0,5$

assim; 


\section{$-0,5 \cdot 20,50+162,80=152,55$}

Deste modo, conforme o modelo acima, o resultado que apresentaria uma divisão igual das partes seria $R \$ 152,55$ neste caso, nota-se que o comprador exibe um maior poder de barganha em comparação com o vendedor, deste modo para se encontrar a diferença do poder de barganha, pode-se analisar o ponto de desacordo, pois, o ponto de desacordo de uma das partes, mais próximo do preço acordado, sugere o menor poder de barganha.

Diante de uma igualdade no poder de barganha, para o caso da feira, o preço real de venda, como mostrado anteriormente, foi de $R \$ 145,34$, onde para se alcançar tal resultado, utilizando-se a mesma solução de Nash, o ponto de desacordo do comprador seria de $R \$ 148,38$ e não de $R \$ 162,80$, dessa forma, sabese que o poder de barganha do vendedor é menor que o do comprador, pois ao flexibilizar o ponto de desacordo do comprador para baixo, o vendedor cedeu vantagens ao comprador para assim poder apregoar a venda.

Outra explicação para os jogos cooperativos foi dada por Rubinstein, o seu modelo consegue explicar o motivo dessa diferença do poder de barganha e consequentemente essa flexibilização do pondo de desacordo, por meio da paciência de cada jogador, atribuída por um fator de desconto. Em seu teorema nas fórmulas 05 e 06 Rubinstein (1982) explica, que ambos os jogadores, que no caso da feira retratam o comprador e o vendedor de gado, diante de paciências distintas acabam tendo resultados que diferem no poder de barganha.

Para modelar essa situação de impaciência, Rubinstein adiciona um fator de desconto $\delta$ no tempo, onde para cada oferta do vendedor e do comprador $\left(\delta_{v}, \delta_{c}\right)$, na qual $0<\delta_{v}<1$ e $0<\delta_{c}<1$ seria adicionado esse custo. Assim seu teorema mostra, que, caso haja um desconto maior no tempo para um dos jogadores, o jogador com maior desconto apresentaria uma paciência maior e consequentemente seu poder de barganhar também.

No ambiente da feira, por meio dos próprios consumidores e vendedores, foram obtidas as médias de quanto perdem ambos, caso não negociem um animal. Com os dados referentes às médias de custo de não negociar os animas, é possível inferir quais dos jogadores apresentam maior impaciência, sendo tal custo à representação do fator de desconto de Rubinstein no tempo, tendendo ao infinito, ou seja, quanto maior o custo, caso não negocie o animal, maior a impaciência e menor o fator, e consequentemente menor poder de barganha, contribuindo, por exemplo, 
para uma flexibilização do ponto de desacordo do modelo de Nash, deste modo forçando um dos jogadores a uma negociação injusta.

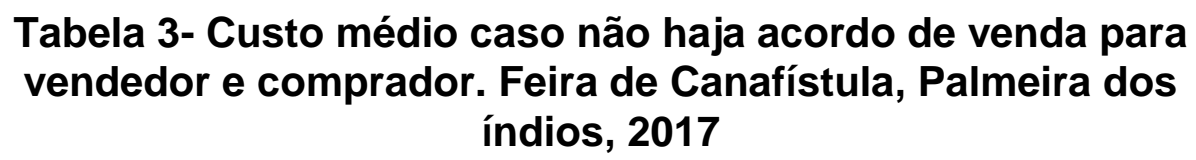

\begin{tabular}{c|c|c|c|}
\hline Jogador & $\begin{array}{c}\text { Média do custo } \\
\text { caso não haja } \\
\text { negociação }\end{array}$ & Desvio padrão & $\begin{array}{c}\text { Erro } \\
\text { amostral }\end{array}$ \\
\hline Comprador & 20,5684 & 21,8412 & $\pm 5,263$ \\
\hline Vendedor & 72,5469 & 64,0077 & $\pm 32,23$ \\
\hline
\end{tabular}

Fonte: Autores a partir de dados primários da pesquisa.

Nota: Preços correntes em Reais de novembro de 2017.

A tabela 3 mostra as médias de cada um dos jogadores, que correspondem a seus custos por animal, caso não haja negociação, evidenciando assim um maior custo para o vendedor em comparação ao comprador. A tabela 3 também apresenta o desvio padrão e o erro amostral. Nota-se que o desvio padrão e o erro amostral do vendedor, encontram-se altos, devido ao menor número de entrevistas obtidas com vendedores, por conta da dificuldade durante a sua atividade de negociação no evento, onde nem todos permitiram que a entrevista fosse realizada. Embora o erro seja bastante alto, nota-se que a diferença media é estatisticamente relevante, conforme os erros amostrais, evidenciando a grande disparidade entre o customédio do animal não negociado do vendedor, e do comprador.

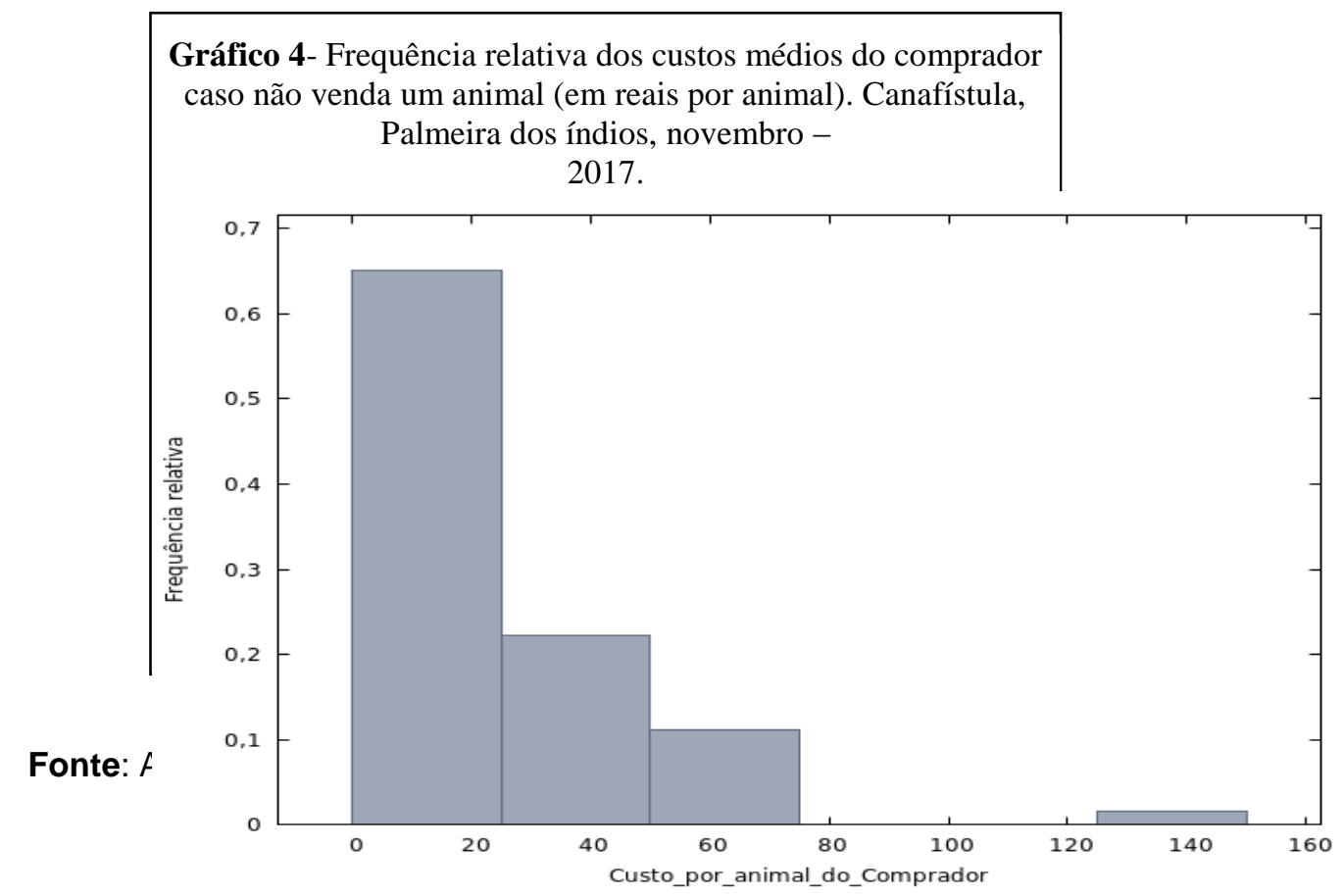


O gráfico 4 acima mostra os valores por custo do animal do comprador, caso não compre o animal, ou seja, seu custo de oportunidade, somada as despesas com transporte e alimentação. O resultado aponta muito fortemente para uma frequência, onde os custos encontram-se bastante próximos de zero a vinte reais. A frequência

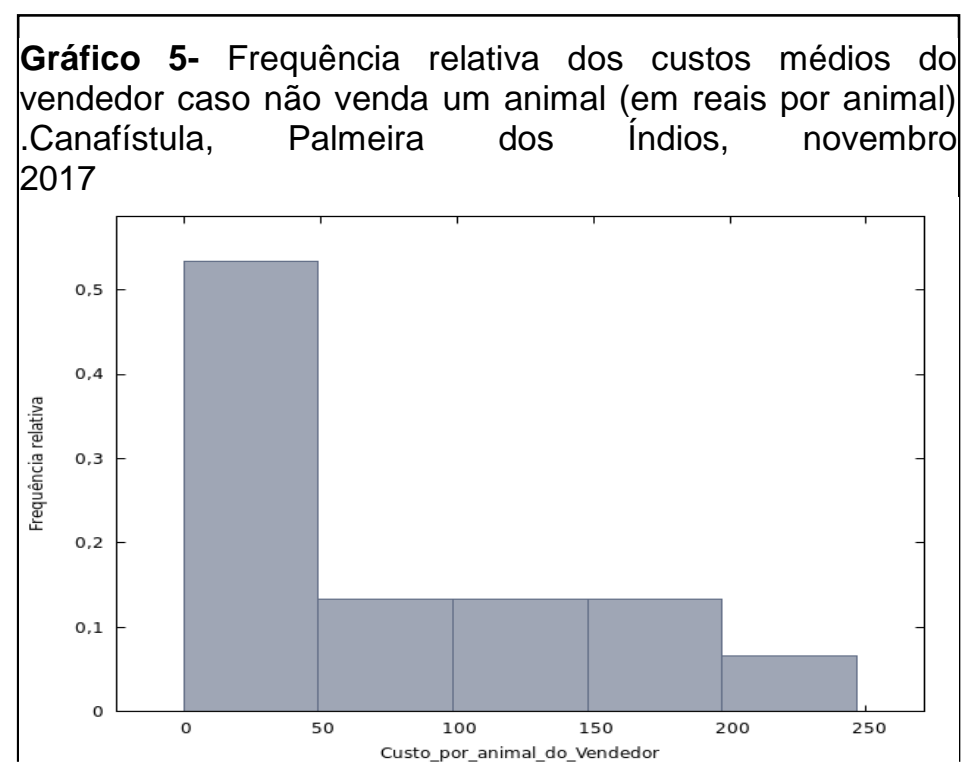

relativa cai severamente para custos acima de quarenta reais.

Fonte: Autores, 2018, a partir de dados primários da pesquisa.

O gráfico 5 acima mostra os valores por custo do animal do vendedor, caso não compre o animal, neste caso encontram-se somadas várias despesas. A frequência relativa dos custos é maior para valores entre zero e cinquenta reais com valores correntes de novembro de 2017, porém quase a outra metade dos resultados corresponde a valores acima de cinquenta reais.

Os resultados representam os custos do comprador e do vendedor, caso permaneçam no seu ponto de desacordo, portanto sem realizarem a negociação. Os resultados sugerem que as perdas para o vendedor sejam bem maiores, consequentemente, aplica-se um fator de desconto menor para o vendedor, a cada rodada de negociação, onde não há um acordo. Dessa forma, $\delta_{v}<\delta_{c}$ que reduz drasticamente seu poder de barganha, o que se supõe também, de forma empírica, $o$ ato de flexibilizar o ponto de desacordo, em teoria, para que assim, o animal seja vendido. 


\section{Considerações Finais}

Diante do exposto, conclui-se que as feiras de gado do interior de Alagoas, além de oferecer um importante canal para a comercialização de bovinos, também se trata de um mercado, onde a prática da barganha está intrinsecamente presente em seu sistema. Portanto, na existência de uma diferença sensível no poder de barganha entre vendedores e compradores, tal desequilíbrio tornar-se-ia determinante na resolução do preço final.

Ao se verificar, a partir de testes estatísticos, os valores médios de negociação dos animais, usando como referência a feira de Canafístula em Palmeira dos Índios - AL. Foi possível comparar com as teorias formuladas para o jogo cooperativo da barganha, sendo as teorias da solução de Nash e Rubinstein, que revelaram supostamente a existência de diferenças sensíveis no poder de barganha entre os vendedores e os compradores em média.

Assim, o trabalho diagnosticou que para adequação do preço correspondente com uma situação de igualdade no poder de barganha seria necessária uma virtual flexibilização do ponto de desacordo do comprador, portanto em comparação com o modelo da solução de Nash haveria uma diferença no poder de barganha. De outra forma, os resultados mostram também uma diferença na paciência do vendedor, que quando comparado com o teorema de Rubinstein revelaria uma taxa de desconto menor durante as rodadas de barganha, logo confirmando também uma desvantagem para o vendedor durante as comercializações.

Embora o trabalho tenha suas limitações, sendo apenas de intuito ilustrativo, ao utilizar para tal as teorias dos jogos cooperativos, no comparativo com dados empíricos, sem haver a possibilidade de atestar os fenômenos mediante o caráter representativo dos modelos utilizados. Os resultados podem ser importantes para colaborar no diagnostico, e causas, diante da hipótese da presença de falhas de mercado, em tais e respectivos eventos.

$\mathrm{O}$ artigo ensaio mostra as peculiaridades relativas a um tipo de ambiente de mercado spot no mercado interno brasileiro de bovinos, onde existem outros canais de comercialização até bem mais sofisticados, os leilões, por exemplo; quando são comercializados animais com qualidade genética geralmente superior. De qualquer forma os gráficos presentes nos apêndices mostram a abrangência regional de uma feira de gado no interior de Alagoas. Além disso, a fundamentação teórica permite um olhar diferenciado sobre o tema. 


\title{
REFERÊNCIAS
}

BIERMAN, H. Scott; FERNANDEZ, Luiz. Teoria dos Jogos. $2^{\underline{a}}$ edição. 2013.

DIAS, Marco Antônio Guimarães. Opções reais híbridas com aplicações em petróleo.

Rio de Janeiro: PUC, Departamento de Engenharia Industrial, 2005. Disponível em:<http://marcoagd.usuarios.rdc.puc-rio.br/pdf/tese_doutor_marco_dias. pdf>. Acesso em 04 nov. 2014.

IBGE. Sistema IBGE de Recuperação Automática - SIDRA. Disponível: em:<https://sidra.ibge.gov.br/pesquisa/ppm/quadros/brasil/2016>. Consultado em $13 \mathrm{dez}$. 2017.

IBGE. Cartas e Mapas. Disponível:

site.<ftp://geoftp.ibge.gov.br/cartas_e_mapas/mapas_estaduais_e_distrito_federal/politico/20 15/al_se_politico450k_2015.pdf>.Acesso em 11 de fev. 2109.

MAIA, Doralice. S. A Feira De Gado Na Cidade: Encontros, Conversas E Negócios. Revista Formação, João Pessoa, vol. 1, n. 14, p. 12-30, 2007.

SANTOS, Andréa Maria dos. Falta de consciência em problemas de barganha de 2 jogadores. Recife2009. Tese de Doutorado. Universidade Federal de Pernambuco. Disponível em:<http://www.contabeis.ufpe.br/ppge/images/dissertacoes/dissertacao097.pdf>. Acesso em 05 jan. 2016.

LIRA, Fernando José. Formação da Riqueza e da Pobreza de Alagoas. Maceió: Edufal, 2007.

NASH JR, John F. The bargaining problem. Econometrica, v. 18, n. 2, p. 155-162, 1950.

RUBINSTEIN, Ariel. Perfect equilibrium in a bargaining model. Econometrica: Journal of the Econometric Society, p. 97-109, 1982.

\section{NOTAS DE AUTOR}

\section{CONTRIBUIÇÃO DE AUTORIA}

\begin{abstract}
José Adeilton da Silva Filho - Concepção. Coleta de dados, Análise de dados, Elaboração do manuscrito. André Maia Gomes Lages - Elaboração do manuscrito. Coleta de dados. Participação ativa da discussão dos resultados; Revisão e aprovação da versão final do trabalho.

Maria da Graca Derengowski Fonseca - Participação ativa da discussão dos resultados; Revisão e aprovação da versão final do trabalho.
\end{abstract}

\section{FINANCIAMENTO}

Não se aplica.

\section{CONSENTIMENTO DE USO DE IMAGEM}

Não se aplica.

APROVAÇÃO DE COMITÊ DE ÉTICA EM PESQUISA

Não se aplica.

\section{CONFLITO DE INTERESSES}

Não existem conflitos de interesse: financeiros, pessoais, entre possíveis revisores e editores, ou possíveis vieses temáticos. 


\section{LICENÇA DE USO}

Este artigo está licenciado sob a Licença CreativeCommons CC-BY. Com essa licença você pode compartilhar, adaptar, criar para qualquer fim, desde que atribua a autoria da obra.

\section{HISTÓRICO}

Recebido em: 01-02-2019

Aprovado em: 15-03-2019 